\title{
L'étude des matériaux organiques dans les tombes
} du haut Moyen Âge : un apport à la connaissance des pratiques funéraires et des vêtements?

Projet collectif de recherche (2013)

\section{Florence Carré}

\section{OpenEdition}

\section{Journals}

Édition électronique

URL : https://journals.openedition.org/adlfi/17770

ISSN : 2114-0502

Éditeur

Ministère de la Culture

\section{Référence électronique}

Florence Carré, «L'étude des matériaux organiques dans les tombes du haut Moyen Âge : un apport à la connaissance des pratiques funéraires et des vêtements ? » [notice archéologique], ADLFI.

Archéologie de la France - Informations [En ligne], Normandie, mis en ligne le 11 juillet 2016, consulté le 21 septembre 2021. URL : http://journals.openedition.org/adlfi/17770

Ce document a été généré automatiquement le 21 septembre 2021.

(C) ministère de la Culture et de la Communication, CNRS 


\title{
L'étude des matériaux organiques dans les tombes du haut Moyen Âge : un apport à la connaissance des pratiques funéraires et des vêtements?
}

\author{
Florence Carré
}

\author{
Lien Atlas (MCC) : \\ http://atlas.patrimoines.culture.fr/atlas/trunk/index.php? \\ ap_theme=DOM_2.01.02\&ap_bbox $=0.180 ; 49.501 ; 0.213 ; 49.526$
}

\begin{abstract}
L'étude des éléments organiques préservés dans les tombes du haut Moyen Âge à proximité des objets métalliques a été développée ces vingt dernières années en Suisse et en Allemagne. Elle apporte des renseignements essentiels sur le costume et les pratiques funéraires, en particulier sur la manière de placer et de présenter les objets dans la sépulture, ainsi que sur la présence de dépôts ou d'aménagements végétaux. Le PCR a pour objectif de promouvoir cette approche en France, où elle est encore peu fréquente et reste souvent superficielle. Sa prise en compte dès la phase de terrain est rare bien qu'elle s'avère essentielle. Il s'agit de renouveler, par ces études, une partie des problématiques du domaine funéraire en complétant le faisceau des indices fournis par la pratique, surtout française, de l'anthropologie de terrain.
\end{abstract}




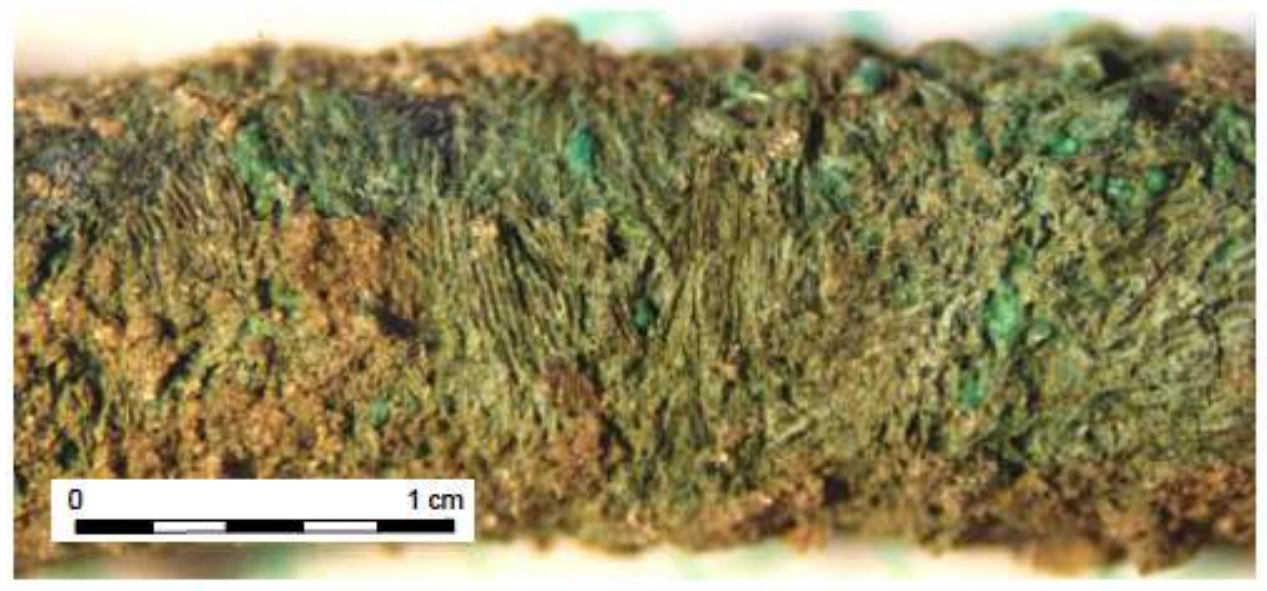

\section{Fig 01 - Harfleur, Les Coteaux du Calvaire}

Poils animaux montrant que la grande épingle de la sépulture 1485 fermait au cou de la défunte une fourrure ou un textile en laine feutrée

A. Rast-Eicher

2 Le site choisi pour illustrer l'intérêt de cette démarche est une importante nécropole mérovingienne fouillée en 2011 et 2012 par la société Archéopole sur la commune d'Harfleur (76). Près de 650 sépultures et réductions de corps ont été mises au jour dans un espace d'environ $600 \mathrm{~m}^{2}$ enclos par les murs d'un ensemble monumental antique. L'utilisation de cette nécropole débute vers la fin $d u v^{e}$ ou le début du $v^{e} s$. et s'achève vers le début $d u v_{\text {VIII }} \mathrm{e}$. Les sépultures, parfois très bien conservées, sont souvent accompagnées d'objets dont certains comportent des traces de matériaux organiques.

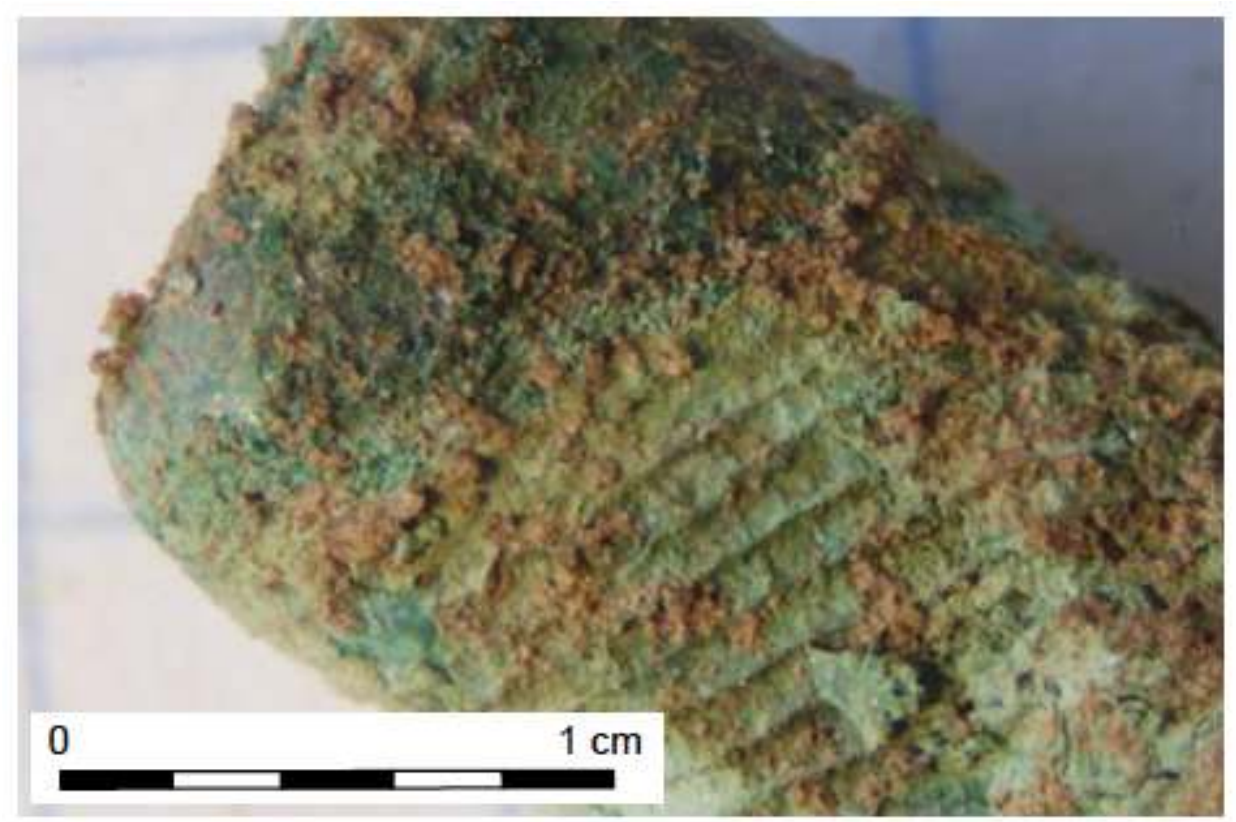

Fig 02 - Harfleur, Les Coteaux du Calvaire

Restes de VÉgétauX, PRobablement d'Un Bouquet, SUR LE BRACELet de LA SÉPULTURE 1793 A. Rast-Eicher 


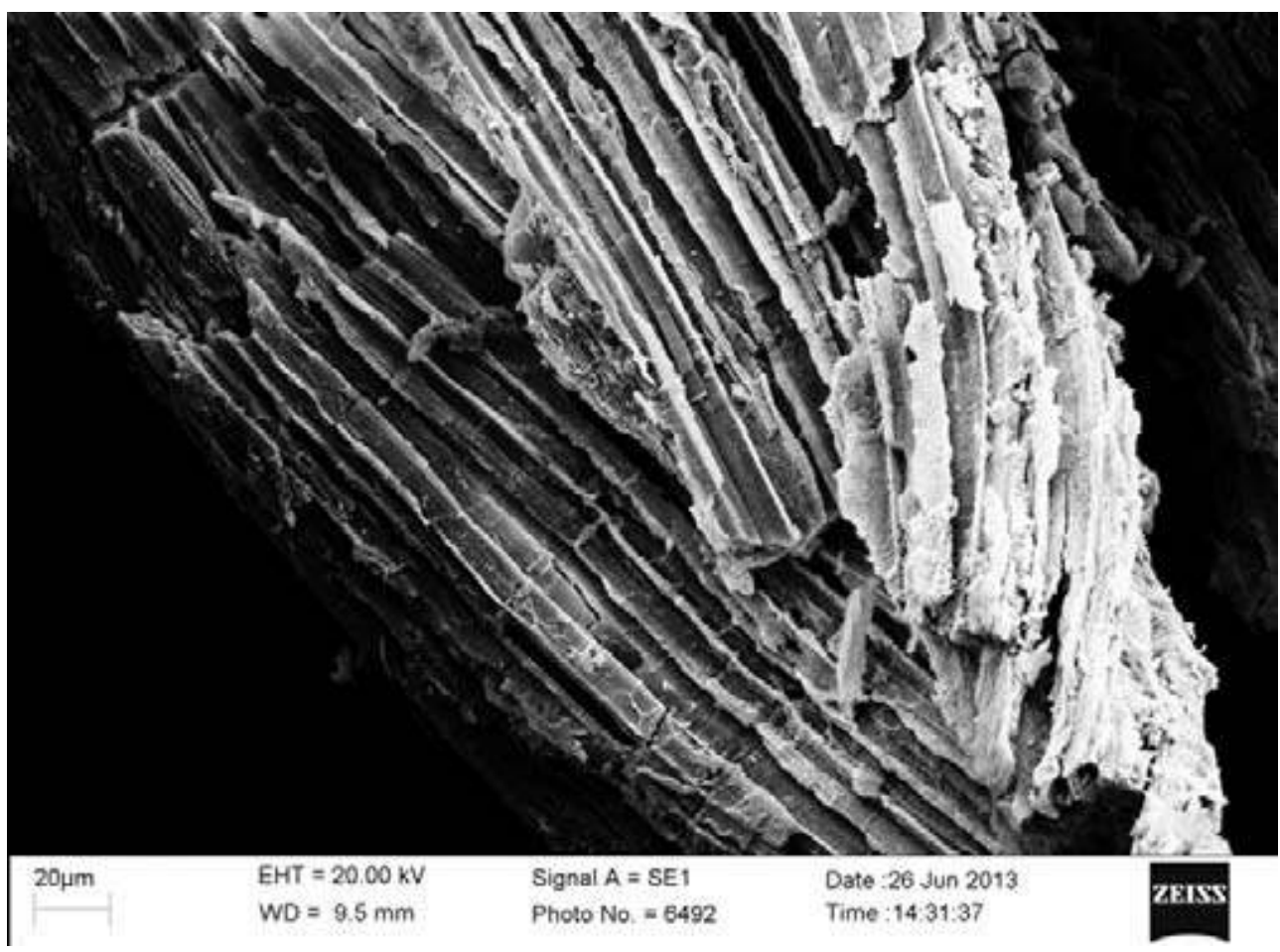

Fig 03 - Harfleur, Les Coteaux du Calvaire

FIBRES DE LIN SE TROUVANT AU REVERS D'UNE FIBULE DE LA TOMBE 1485, VUES AU MICROSCOPE À BALAYAgE ÉLECTRONIQUE

A. Rast-Eicher

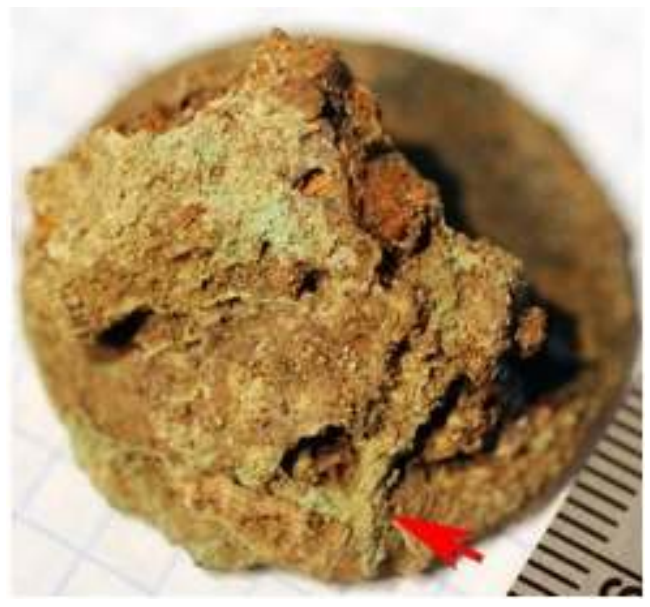

Fig 04 - Harfleur, Les Coteaux du Calvaire

BRIDE AU REVERS D'UNE fiBULE DISCOÏDE DE LA TOMBE 1793

A. Rast-Eicher 


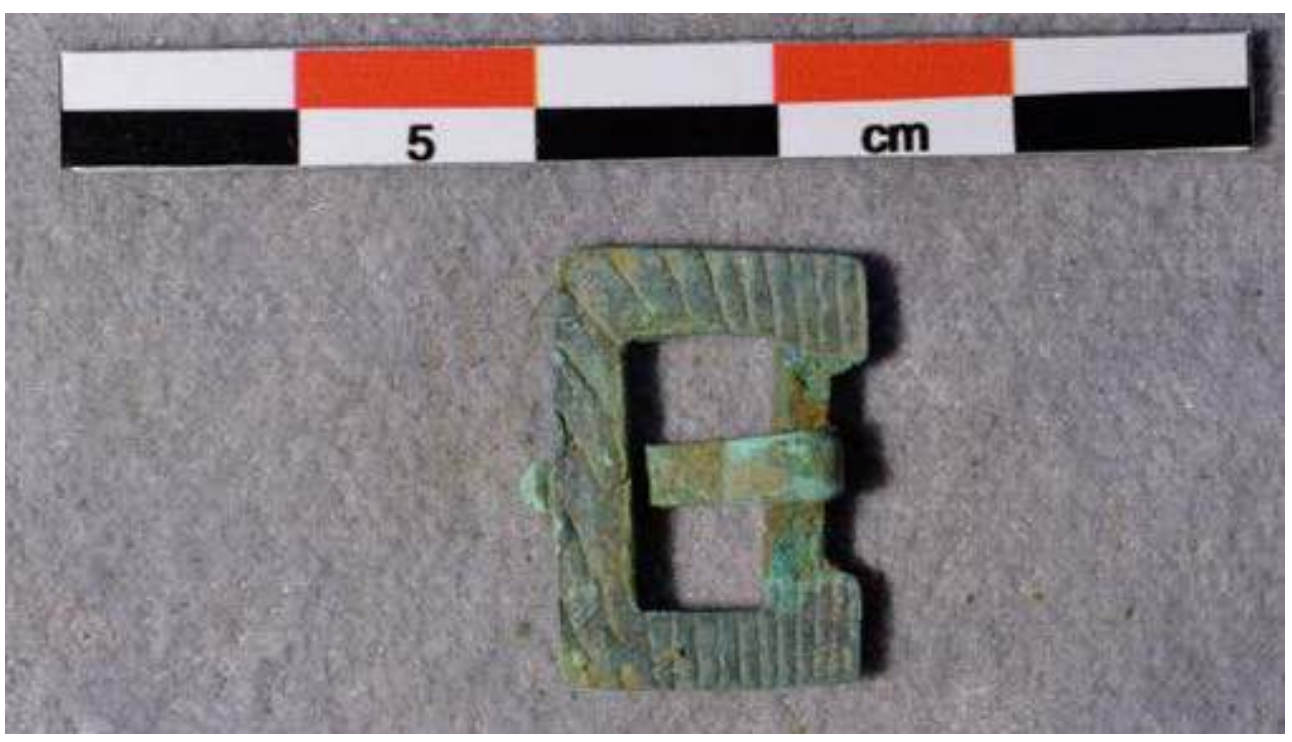

Fig 05 - Harfleur, Les Coteaux du Calvaire

TRACES DE MOULAgE À L'OS DE SEICHE SUR UNE BOUCLE EN ALLIAgE CUIVREUX DE LA TOMBE 1553 B. Bell

3 Sur le terrain, la meilleure méthode pour préserver les vestiges organiques est de prélever en motte entourée de bandes plâtrées puis de congeler le tout jusqu'à l'étude. Ce mode opératoire, long et coûteux, n'a pas été mis en place. En revanche, les objets n'ont pas été détourés au plus près; ils ont parfois été prélevés en mottes mais le plus souvent en levée directe, en conservant la terre au revers.

Le nombre de tombes et l'abondance de mobilier métallique ne permet pas d'envisager une étude exhaustive des vestiges organiques. L'équipe de recherche a donc sélectionné des ensembles bien conservés comportant des types d'objets susceptibles d'alimenter la problématique des vêtements ou des accessoires vestimentaires. En 2013, trois jours d'étude ont eu lieu à l'atelier Bell, alternant le dégagement des objets par le restaurateur, B. Bell, et l'observation des matières organiques par A. Rast-Eicher (société Archeotex). Cette collaboration a conduit à une modification du protocole habituel de restauration, afin de mieux prendre en compte dorénavant les vestiges organiques.

5 Deux tombes féminines datables entre 520-530 et 600-610 ont été documentées. La tombe 1485 est caractérisée par la présence d'une grande épingle au niveau du cou, de deux fibules discoïdes à décor cloisonné, l'une trouvée au niveau du sternum et l'autre à la taille, de plusieurs petits anneaux en alliage cuivreux alignés entre les fibules, de perles, d'une boucle de ceinture et d'aiguilles. La tombe 1793 contient également deux fibules ainsi qu'un bracelet, une boucle de ceinture, une plaque de châtelaine, un grand anneau et un couteau.

$6 \quad$ Parmi les résultats les plus remarquables, des brides ont été identifiées sur les deux paires de fibules. Elles sont destinées à éviter de percer le tissu, ce qui l'abîme. Ce mode de fixation a été déjà observé en Suisse et en Allemagne. Dans la tombe 1485, la grande épingle placée au cou est piquée dans une fourrure ou un textile de laine feutrée, ce qui est assez inhabituel. La fonction des petits anneaux a été précisée : ils semblent reliés entre eux par une lanière de cuir et cousus sur un textile, peut-être le vêtement. Ils participent probablement à la fixation de ce dernier. Dans la sépulture 1793, des restes 
botaniques sont présents sur le bracelet et suggèrent un bouquet tenu dans la main gauche. Des observations techniques ont en outre été effectuées par B. Bell, qui a mis en évidence la pratique du moulage à l'os de seiche, encore peu reconnue.

INDEX

Index géographique : Haute-Normandie, Seine-Maritime (76), Harfleur

Mots-clés : nécropole, sépulture, bride, vestige organique

operation Projet collectif de recherche (PCR)

Index chronologique : haut Moyen Âge

\section{AUTEURS}

FLORENCE CARRÉ

SRA Haute-Normandie 